\title{
Informal mobile learning in nurse education and practice in remote areas-A case study from rural South Africa
}

\author{
Christoph Pimmer ${ }^{\mathrm{a}, *}$, Petra Brysiewicz ${ }^{\mathrm{b}}$, Sebastian Linxen ${ }^{\mathrm{a}, 1}$, Fiona Walters ${ }^{\mathrm{b}}$, Jennifer Chipps ${ }^{\mathrm{b}}$, Urs Gröhbiel ${ }^{\mathrm{a}, 1}$ \\ a learning.lab/Institute for Information Systems, University of Applied Sciences and Arts Northwestern Switzerland, Peter Merian-Strasse 86, 4002 Basel, Switzerland \\ ${ }^{\mathrm{b}}$ School of Nursing and Public Health, College of Health Sciences, Desmond Clarence Building, University of KwaZulu-Natal (UKZN), Durban 4000, KwaZulu-Natal, South Africa
}

\section{A R T I C L E I N F O}

\section{Article history:}

Accepted 25 March 2014

Keywords:

Educational technology

Mobile phone

Mobile learning

Ubiquitous learning

Nursing Education

Rural health

Distance Education

\begin{abstract}
S U M M A R Y
Background: With the proliferation of portable digital technology, mobile learning is becoming increasingly popular in nursing education and practice. Most of the research in this field has been concentrated on small-scale projects in high income countries. Very little is known about the ways in which nurses and midwives use mobile technology in remote and resource poor areas in informal learning contexts in low and middle income countries. Objectives: To address this gap, this study investigates whether nurses use mobile phones as effective educational tools in marginalized and remote areas, and if so, how and why.

Setting and Methods: In rural South Africa, 16 nurses who attended an advanced midwifery education program, facilitators and clinical managers were interviewed about their use of digital mobile technology for learning. Techniques of qualitative content analysis were used to examine the data.

Results: Several rich "organically-grown", learning practices were identified: mobile phone usage facilitated (1) authentic problem solving; (2) reflective practice; (3) emotional support and belongingness; (4) the realization of unpredictable teaching situations; and (5) life-long learning.

Conclusions: It is concluded that mobile phones, and the convergence of mobile phones and social media, in particular, change learning environments. In addition, these tools are suitable to connect learners and learning distributed in marginalized areas. Finally, a few suggestions are made about how these insights from informal settings can inform the development of more systematic mobile learning formats.
\end{abstract}

(c) 2014 Elsevier Ltd. All rights reserved.

\section{Introduction}

\section{Mobile Phones and Nursing Education}

Mobile phones and smartphones are increasingly popular in nursing education and practice (Garrett and Klein, 2008). They support a broad range of educational practices in formal education settings as well as in clinical environments (George et al., 2010). For example, the use of smartphones by Taiwanese nursing students as clinical examination tools in simulations proved to result in higher learning outcomes compared to a control group who used pen and paper to record and evaluate patient symptoms (Wu et al., 2011). In a British study, multimedia podcasts on iPods were used directly at the bedside to support the

\footnotetext{
* Corresponding author. Tel.: +4161279 18 49; fax: +41612791798.

E-mail addresses: christoph.pimmer@fhnw.ch (C. Pimmer), brysiewiczp@ukzn.ac.za (P. Brysiewicz), sebastian.linxen@fhnw.ch (S. Linxen), walters@ukzn.ac.za (F. Walters), chippsj@gmail.com (J. Chipps), urs.groehbiel@fhnw.ch (U. Gröhbiel).

URLs: http://www.fhnw.ch (C. Pimmer), http://www.fhnw.ch (S. Linxen), http://www.fhnw.ch (U. Gröhbiel).

1 Tel.: +416127918 49; fax: +41612791798.
}

learning of midwives regarding the Newborn Infant Physical Examination (Clay, 2011). The analysis of the small-scale pilot revealed that the tool was well received and the participants specifically appreciated the "just-in-time" learning facilitated by these devices. Similarly, studies from the US and Canada come to the conclusion that nurses and nursing students view mobile devices as effective means to support their learning in the workplace by enabling access to various sources of expertise in decision making processes. Reference tools such as drug and diagnostic/ laboratory applications were found to be particularly popular and valued (Garrett and Klein, 2008; George et al., 2010; Kenny et al., 2009).

In addition to the provision of information and communication features, a mobile e-portfolio allowed Canadian students to document their clinical experiences using different modes including text, audio and image. The students greatly valued the reference functions, but also appreciated the opportunity to capture clinical events in the form of photographs (Garrett and Jackson, 2006). The study also referred to the potential of mobile connectivity to prevent isolation in clinical placements. Young et al. (2010) specifically examined this aspect and found that UK nursing students used the texting facility of their own mobile phones as an additional support mechanism to interact with peers and mentors while working in placements. Their findings showed that 
even those students who did not use this facility appreciated it as a potential means of contact when feeling isolated in the clinical placement. Similarly, in another UK study reported by Morley (2013), digital technology was used to support learning in clinical placements and to address professional isolation whereby a range of Web 2.0 tools was piloted to support peer and learner-tutor interactions of nursing students working in isolated placements settings. One of the most popular tools was a Facebook group with high levels of learning interactions. Although the author provides no details, it is noted that students increasingly access this social network site by means of their mobile phones. Mobile phones as educational tools in resource limited settings.

What most of the literature has in common is that the studies were conducted in high income contexts, predominantly in Europe, the US and Australia. Very little is known about the ways in which nurses and midwives use mobile technology in remote and resource poor areas in informal learning contexts in low and middle income countries.

In these countries nurses and midwives have an important role for the delivery of health services and they are considered to be the backbone of the health systems due to a lack of other qualified health professionals (Green, 2006). However, these nurses are often professionally isolated and receive little support and training; many leave the profession or migrate to high income countries (Raisler and Cohn, 2005).

Against this background, international organizations such as UNICEF, ITU and the World Bank have developed high expectations towards mobile phones to support and empower health workers, including nurses and midwives. This is specifically relevant in the context of the Millennium Development Goals, regarding mother and child health and HIV/AIDS. (Holmes, 2010; ITU Press Release, 2010; The World Bank, 2012). However, little is known how mobile devices are being used to support nurses in their learning practices. In an article discussing information technology for nurses, the use of mobile technology is seen as a great opportunity, specifically in Africa. Information and communication technologies in general were deemed as a possible means to address some of the factors to out-migration, such as isolation and lack of educational opportunities (Abbott and Coenen, 2008).

\section{Methodology}

\section{Research Question and Sampling}

In light of the expectations and gaps identified in the literature, the following research question was defined:

Do nurses in disadvantaged and remote areas use mobile phones as effective educational tools, and if so, how?

Addressing aspects of maternal and child health, this study was centered primarily on nurses who attended an advanced midwifery education program in rural and disadvantaged areas in a province of South Africa. In contrast to other provinces in South Africa, this setting can be characterized by a high percentage of people living below the poverty line, high infant and adult mortality (Coovadia et al., 2009). Nurses in these settings often work in isolation and have very poor access to postbasic education, continuing education and up-to-date evidence-based information. In order to access education, these nurses are expected to travel far distances away from their place of work and home.

In selecting the people and roles typically involved in nursing/ midwifery practice and education, we used typical case sampling (Patton, 1990). To cover a broad range of potential learning practices related to formal education as well as informal workplace learning, nurses in the following roles were involved: (1a) eight registered nurses in formal education settings who attend a decentralized education program for advanced midwifery at a University in South Africa; (1b) these participants worked at the same time as registered professional nurses in clinical settings; (2) four nurse facilitators, who support the midwifery students in crossing the boundaries between the formal education program and their work; and (3) three nurse managers, who have an overview of work, learning practices and needs of nurses in their clinics. To involve the managers, we visited three sites that represented typical health service centers of rural South Africa. We approached nursing students and facilitators when they gathered for a lecture at the university. In addition, video interviews were conducted using the university's videoconferencing system.

\section{Data Collection}

After obtaining ethical approval from the University, the research team visited three rural sites to interview the participants. Between June and August 2012, 16 participants were interviewed. Before each interview, it was ensured that all interviewees participated voluntarily. In addition, the confidentiality of the participants was ensured and written informed consent was obtained from every participant. All of the participants allowed the conversations to be tape-recorded.

For the semi-structured interviews, an initial question guide was prepared that comprised questions on learning practices in work and university settings, with a specific focus on mobile phone usage and perceived implications.

\section{Data Analysis}

All interviews were audio-taped, transcribed, and analyzed using the software Nvivo Version 8 (QSR International Pty Ltd, Doncaster, Vic, Australia). The analyses followed the principles of inductive category formation, a technique of qualitative content analysis suggested by Mayring $(2000,2004)$. According to the research question, the selection criteria and the level of abstraction for the categories were broadly defined as socio-cognitive and socio-cultural forms of learning. This is a scope which, according the mobile learning examples in the introductory literature review, and recent theoretical works (Pachler et al., 2010; Pimmer et al., 2010) is suitable to address the breadth of the educational practices supported by mobile technology. Broadly speaking, sociocognitive perspectives connect cognitive and constructivist views of learning. Socio-cognitive perspectives emphasize that learning needs to be situated in tasks and problem solving in real-life contexts (Kirschner, 2006). This is of particular relevance for health professions, where much of the learning is routed in the workplace, in the form of authentic and problem-based learning (Norman and Schmidt, 1992; Slotnick, 1999). Socio-cultural learning perspectives are centered on the notion of participation: the main purpose of meaning making and learning is for learners to progress from peripheral to full participation in public and professional life. Lave and Wenger (1991) elaborated their ground breaking theory of community of practice and situated learning using the example of midwives, who 'absorb' skills by participating in communities of practice in resource-poor contexts in Yucatan (Jordan, 1989). Accordingly, the analysis departed from a broad understanding of learning that included work-related learning activities (in particular critical thinking and problem solving) as well as any signs that indicated a participation of an individual in a community of learners and practitioners.

The design, analysis and interpretation were jointly conducted by researchers from nursing/medical sciences and social and educational researchers to prevent researcher and disciplinary bias (Pope et al., 2000). The principal investigator (CP) coded all of the transcripts. Two researchers independently read, re-read and interpreted approximately $25 \%$ of the data. The findings were critically discussed by all authors until consensus was achieved. For respondent validation (Mays and Pope, 2000), the interviews were re-conducted with three participants, one facilitator and two students. The preliminary findings were presented to the interviewees and were validated by them. 


\section{Results}

The analysis yielded five main themes, i.e. learning practices, which are presented below:

\section{Authentic Problem Solving}

The use of mobile phones enabled and supported learning throughout patient related problem solving processes. This was often prompted by a patient case that was outside the learners' competencies. For example, the participants indicated that they used their mobile phones to involve various virtual communities in "on-site" problem-solving processes. In doing so, they created a mobile and blended learning environment. One facilitator described how students accessed Facebook communities to ask for support from their peers in these situations:

"They do it on Facebook, and they have a group, or [..] they start to ask their friends there [...] Like someone will ask how to go about, if you are having a client who is having this and this problem and someone else is going to answer. That is how you better check this and do one, two, three. Thus, getting a solution."

These communities were fragmented in geographical and virtual spaces. Midwifery students lived in different and under-sourced areas and worked in diverse hospitals. In the case of immediate and urgent questions, students tended to use synchronous communication functions to connect with their virtual communities and would contact one of their facilitators by chatting, texting or phoning. One facilitator described a situation in which she had been consulted by means of a (synchronous) phone call:

"The one [midwifery student] was having a breech delivery [in a remote clinic ...]. That is a complicated case. [...] Then I asked, what do you think? She said, I am thinking this one is complicated, it needs to be done caesarean. [.... I asked:] Have you checked whether the woman is fully dilated or not? Because if she is fully dilated you cannot send her thirty kilometers by ambulance or by her car. [...] if she is fully dilated, she is about to deliver. Let her deliver in your hands in the clinic."

Although there were also formal ways of consulting doctors in workbased settings, participants valued phone-based problem solving because of the immediate access to resources and rapid feedback from their virtual communities. Communication in the case illustrated above included weighing and discussing options and lasted until an initial solution was found. Thus, it had a direct impact on patient management: the patient remained in the remote clinic due to certain health conditions. The knowledge was co-constructed in that the midwifery student strongly contributed to solving the case. In doing so, the facilitator deliberately guided and directed the student. The above excerpts also reveal how learners used mobile phones to virtually link formal education systems (facilitators) to clinical processes, thereby connecting education and work communities.

In addition to involving virtual communities in inquiry processes, many participants indicated that they searched for relevant online information to support inquiry processes in both work-based and course settings by using the search engine, Google, on their mobile phones. A nursing student explained how this practice contributed to her situated understanding and meaning making:

"I was working in the ICU [...]. Consultants [...] said the child had PPHN, and I was not familiar with the term, [...] so I had to look it up for myself, to see in relation to the treatment what the child was getting and what was the cause of all this. I think that was quite useful because then I [...] had a clear picture immediately. [...] It was there, the information was there at that moment. [...] I could actually share the information I had with my colleagues."

\section{Reflective Practice}

The excerpt above also revealed another important concept: sharing information at a later point in time with colleagues in virtual spaces as well as with on-site colleagues by showing them the information on the phone. Mobile phones facilitated and mediated group discussion and reflection. Some participants reported using their mobile phones in diverse ways to document and/or share, discuss and reflect on professional experiences in communities. Students and facilitators described how they occasionally used phones to document work experiences in the form of photographs and shared them in the classroom at a later time.

"When we are together [in school settings], we share and discuss the photos. Some [conditions] we learn in school take a long time to see [in practice settings]. So, when you witness this condition and you are not together with your colleagues, you take this picture. [...] Then you look at the picture and [later] discuss it, if it corresponds with what we have learned." (Nursing student).

The two previous empirical extracts show how multimodal representations (text and images) facilitated the connection of situated learning across different communities over time and, in the second example, also across geographical space. This example also illustrates how phones mediate and iteratively connect learning in work and formal education settings. The participants also involved (exclusively) virtual communities on social network sites in their reflective processes. One participant reported using Facebook to asynchronously discuss and reflect on professional experiences. She provided the example of a closed Facebook alumni group that was formed several years ago by students from her basic nursing education. These students had specialized in various areas of nursing and worked in different geographic regions. Using a Facebook group, the nurses consulted each other through straightforward and supportive feedback in addressing, for example, unexpected interdisciplinary patient cases, situations in which knowledge from different nursing specializations needed to be combined, or practices that a student viewed as beneficial to patient treatment as well as to her own competence development.

"Sometimes you use the group afterwards, after you have managed the patient, to see how you went, where you went wrong, how you did, or sometimes they say I messed up. Then, they give you the reasons, or sometimes they will tell you, oh, well done, but you missed that and that."

\section{Emotional Support and Belongingness}

Beyond the solving of factual, clinical problems, a number of emotional and social communication practices were observed regarding the use of mobile phones. Mobile interaction often involved emotions, such as when midwifery students were "anxious" and then spontaneously activated their communities and other resources for help. The next extract shows that, mobile phone-based emotional support was provided that went far beyond clinical problem solving:

Interviewer: "Do you exchange SMS with your teachers [facilitators]? Nursing student: Yeah, she is like a mother to us, we do. [...] Yeah, even like a family problem, personal problem, we do talk to her."

This statement also demonstrates how learners connect formal education, work and private spaces by means of mobile technology. They discussed details of their lives outside of the course and work setting with facilitators, i.e. beyond their peer milieus.

However, although openness and trust were central aspects in the above example of the Facebook group, participants tied honest and straightforward feedback to the peer characteristics and the nonhierarchical structure of the group. They reported using informal 
language that would not be appropriate with facilitators (who evaluated students). There were concerns that their peers would not willingly report and provide feedback on patient treatment if staff from the formal education system were participating in these groups:

"Others might not tell me straight, a fair answer, because they will know she [facilitator] is also part of the group."

This supports the view that mobile phone usage resulted in the creation of new patterns of media (and related language) use according to the specific microculture; a culture which was, however, different from those of formal education institutions. The observation that students established and engaged in social "mobile" groups in a bottom-up manner points to the cohesive nature of these spaces and to an associated sense of belongingness. In characterizing these spaces participants used inclusive pronouns ("we") and referred to these groups as spaces to which to which they belong:

"Yes, we formed a group, we have defined groups. I belong to the group [...]"

\section{Realization of Unpredictable Teaching Situations}

Learning situations in both the workplace and, to some extent, in the formal educational program are hard to predict as they are shaped by the nature of the problem (e.g., patient cases) as well as by the dynamic environment in which they occur. In this context, mobile phones provide flexibility in arranging and realizing learning situations, particularly regarding formal educational settings: for example, facilitators communicated new or spontaneously changed schedules for lectures by means of their phones to the students:

"[...] For instance, for today, she [facilitator] had to SMS us because we are on leave to let us know that there will be a lecture." (Nursing student)

Outside of formal classroom settings, students spontaneously involved facilitators in particularly interesting patient cases in the clinic by means of their mobiles. Thus, mobile phones facilitated the realization of unpredictable on-site teaching in ways that were not previously possible (and, again, connected formal education and work-based settings more closely).

"[...] We would phone and tell her that [...]maybe if she is close by, she will come around. [...] Then, she will teach us in the real situation, not like we are doing a theory in class." (Nursing student)

Mobile phones were not only used to harness unforeseen opportunities, but also to address challenges in the organization of teaching events that were caused by external dynamics.

.. When I came to town, there were riots, people, the taxis were not working then, they had been stopped. So I phoned one of my colleagues who was already at school to fetch me." (Nursing student)

\section{Life-long Learning}

On a general level, the mobile phone was the most important computational tool for the interviewees. Their use was reported to be a widespread and popular practice, not only within the interviewed sample, but also in the wider nursing community, as expressed by one participant: "Not a single nurse without a mobile phone" (16). Nearly all of the participants used their phones on a daily basis. All of them regularly accessed internet-based applications on their phones, mostly to search for information and for social purposes using text messages, chat or social media. However, the intensity and scope of mobile phone use was linked to age; the participants often reported that younger midwives used mobile phones more broadly and frequently for private, work or learning purposes.
The participants indicated receiving no support from educational or other institutions, such as hospitals, in the use of mobile phones. Moreover, in many places, the use of phones was actually discouraged, as expressed by a nursing manager:

"It's one thing that I do not like to see when I go to the wards. I don't like to see people carrying phones."

In spite of this, however, midwifery students mutually helped each other with the new opportunities provided by mobile technologies. More importantly, many of them reported being encouraged and supported in the use of mobile phones by the younger generation, particularly their children:

"Actually, I was shown by my daughter at home. [...] So I showed my colleagues, yeah." (Nursing student)

The use of these phone functions empowered nurses in a sense that they were provided with more, and more diverse options to participate and engage in social spaces (e.g. religious communities on social networking sites) and to access opportunities for learning not previously possible (e.g. by using mobile internet to search for new posts). Accordingly, the phone has become a central tool for their life, and their lifelong learning:

"It is part of my life now [...] a means of contact, a means of learning. You know, people who have phones just learn a lot." (Nursing student)

The centrality of mobile was also evident from a bodily perspective. Participants often carried their phone in their brassiere, a place where people in South Africa store and hide things that are valuable to them (Seedat, 2006).

\section{Discussion}

The results have a number of conceptual and practical implications. We characterize on the basis of didactic parameters how the mobile phone usage observed can be conceptualized in terms of learning environments; make recommendations for practical improvements including ethical issues; and present options for further research.

\section{Rich Mobile Learning Practices}

It has become evident that mobile devices have a specific potential to support socio-cognitive learning processes in the form of problemsolving and reflection in the workplace. (George et al., 2010; Pimmer and Pachler, 2013). Work-based learning as observed was not restricted to accessing information at the point of care. Social communication functions and apps allowed peer-to-peer co-construction and exchange of local knowledge and emotional support; practices that are closely tied to and affect work processes and patient treatment. Viewed in terms of socio-cultural participation, nurses used their mobile phones to more intensively engage in various social/professional communities in ways that were not possible without mobile technology. In this sense, mobile phones, and in particular the convergence of mobile and social media, can support learners in alleviating professional isolation, as it was also indicated in the literature (Morley, 2013; Young et al., 2010). These findings are also in line with other studies from low resource settings showing how mobile phones support socio-cultural participation and identity formation (Pimmer et al., 2012, 2013a) and enhance professional relationships (Chib, 2010).

\section{The Changed Meaning of Learning Environments}

The identified learning practices such as problem-solving, reflection, emotional support and belongingness to (virtual) social groups, or the use of digital technology for teaching and life-long learning could be 
discussed in light of a number of specific pedagogical concepts. Putting it in the words of Laurillard (2009), mobile technology has not changed "what it takes to learn". What has changed, however, is the meaning and characteristics of learning environments. In the following, we use a number of educational parameters to distill our findings with respect to learning environments: space, degree of formality, tool, synchronicity, prompt, modality, predictability and time span (see Table 1).

The implications of mobile technologies on the characteristics of learning communities are most evident. According to Lave and Wenger (1991) the main way of learning is for a learner to progress from a novice to an "old timer" in a community of practice, for example, a group of midwives. In the field of technology-enhanced learning, Garrison et al. (1999) widely popular community of inquiry framework has also primarily been used to study learning in bounded digital spaces, for example in courses in learning management systems (Mayne and $\mathrm{Wu}, 2011)$; a focus on learning that, in addition, tended to be teacherguided using asynchronous, text-based communication.

We found that learning, as observed, is not restricted any longer to tightly bounded and locally based communities (of practice) or to closed online communities (of inquiry). Nurses in low resource areas use mobile phone functions, particularly social applications, to dynamically connect learning that is distributed in mobile and blended communities across different geographical, social, temporal, and topical as well as virtual and on-site spaces. The examples have shown that nurses used these devices to connect learning in formal education systems, i.e. in the context of the course, with learning in informal learning settings, i.e. the workplace. In this sense, mobile phones can be perceived as boundary crossing tools, as they embed fragmented communities and other knowledge resources in learning processes and, in so doing, they connect nurses working in professional isolation. In the contexts observed in this paper, nurses flexibly used a bundle of different tools, including synchronous and asynchronous communication functions according to situated work and study needs.

Mobile learning was not pre-determined by the teacher, but problem-driven, shaped, and guided by the nature of the problem. In addition, in the educational and work-related use of the mobile phone the learners were not formally supported by education and work institutions, but by their peers and their own children. The participants' learning processes involved multimodal design, including linguistic, audio and visual meanings (see e.g. Cazden et al., 1996). In the settings explored here, relatively stable and predictable learning processes were found in on-site communities such as co-present work and study teams. By contrast, nurses used mobile phones to organize and support learning to better address unforeseen and unpredictable occurrences, characteristics that are typical of clinical settings in general (Pimmer et al., 2013b) and particularly in the changing macro- and socioeconomic health contexts in South Africa (Coovadia et al., 2009). In addition, nurses used mobile phones to connect situated experiences with sources and communities, even across phases of their career trajectories in the sense of life-long learning (Pimmer et al., 2013a).

\section{Practical Implications, Ethical Issues and Recommendations}

Our results from informal, work-related learning settings resonate with some of the findings in the extant literature from US and European contexts, and more formalized and planned education interventions. However, we deem the value of this technology to be even higher in lower income countries because the mobile phone is often the only computational tool available for accessing additional knowledge. It can alleviate professional isolation, which is a much more dramatic problem in developing countries (WHO, 2010), and it also helps learners to respond more flexibly to unpredictable learning situations in dynamic and transforming contexts. As indicated, mobile phones seem to be valuable for connecting school-based education and workplace learning, such as in the form of virtual tutorial support in the workplace or reflective practice.

However, the use of mobile technology does not result in positive effects per se, and brings a number of ethical and practical issues to the fore. These challenges relate to the development and maintenance of professionalism, safe practices, and to the protection of patient privacy in these new media spaces. Responding to these issues, mobile and social media should not be banned or ignored in education and workrelated settings, as we observed in this study. It can be even argued that thorough restrictions on the nurses' use of digital media are not feasible and practical. Instead, nurses should be educated and supported in the systematic development of a broad set of health- and media literacy skills which include the access, analysis evaluation and creation (sharing) of content (Livingstone, 2004). These themes should be integrated into national medical/nursing/midwifery curricula and other training formats. For example, the creation and sharing of patientrelated information across mobile and social media spaces are a highly sensitive topic, specifically when it comes to the exchange of photos. Taking patient photos with (phone) cameras for learning, teaching or joint problem solving represents an indirect therapeutic function (Berle, 2008). Thus, nurses, and other health professionals, should be trained to ask for written consent before taking such a photo, even if it is not identifiable (Bhangoo et al., 2005). This is all the more important because the use of mobile phones and social media is associated with personal and not with professional communication. It is, typically, not perceived as a clinical activity and could be viewed as an invasion of privacy by the patient. Thus, the provision of explicit information and clarification about the purpose of the phone-based activity of the patient is necessary.

Key is also the learners' literacy with respect to the critical analysis and evaluation of content. In this regard, responsibility is shifted from the teacher to the learner, because instructors cannot control and be

Table 1

Connected learning in distributed environments.

\begin{tabular}{|c|c|c|}
\hline Learning environments & Characteristics & Examples \\
\hline Space & $\begin{array}{l}\text { Multiple communities, "mobile" and blended, distributed in social, } \\
\text { temporal, topical, geographical, digital and on-site spaces }\end{array}$ & $\begin{array}{l}\text { Work colleagues, study colleagues, former work/study colleagues living and } \\
\text { working in different sites }\end{array}$ \\
\hline Degree of formality & $\begin{array}{l}\text { Link learning in formal education systems with learning in informal work } \\
\text { settings }\end{array}$ & $\begin{array}{l}\text { Sharing learning experiences at work with peers from work, the course and } \\
\text { lecturers; involving facilitators (from the course) in work process by means of } \\
\text { mobile phones. }\end{array}$ \\
\hline Tool & Boundary crossing tool & $\begin{array}{l}\text { Use of call, text, WhatsApp, Facebook to link different sources to problem } \\
\text { solving and learning processes across different spaces }\end{array}$ \\
\hline Synchronicity & Synchronous and asynchronous & $\begin{array}{l}\text { Chat or talk with facilitators and peers, depending on the urgency of a } \\
\text { questions/problem }\end{array}$ \\
\hline Prompt & Problem-driven, bottom up, peer-peer, according to situated needs & $\begin{array}{l}\text { A more complex or "rare" patient case. Changes in the educational } \\
\text { environment that effect the teaching organization. }\end{array}$ \\
\hline Modality & Multimodal: text, voice, images & Discussing “mobile" images across on-site communities \\
\hline Predictability, stability & Dynamic, unexpected & $\begin{array}{l}\text { Ad-hoc phone-based support, triggered by a more complex patient case, or an } \\
\text { unexpected occurrence. }\end{array}$ \\
\hline Time span & Connecting situational and life-long learning & Reflecting upon a documented patient case with former students \\
\hline
\end{tabular}


involved in all the different media formats and spheres available today. Nursing students need to learn which social and digital sources to trust, how to evaluate trustworthiness, and to be aware of their own boundaries and limitations. However, professionalism within (social) media is not something that can be trained top down exclusively. Instead, teachers and facilitators could co-create social media spaces with their students. In these safe environments, they could trigger students to think reflexively and critically about their own professional experiences, their online personae and their professional online behavior, as suggested by Brown (2010). Learning in these "laboratories" is not characterized by direct instruction, but by enculturation: by teachers and facilitators who model appropriate and sensitive behavior. An additional means to ensure professional behavior is also through the development of guidelines. Berle (2008) suggested the integration of a code of ethics for clinical photography in codes of practice. This approach might well be extended to the general use of mobile and social media in clinical environments.

In view of limitations of mobile communication discussed, and given the embodiment of knowledge and skill development in nursing and medical practice (Jordan, 1989; Pimmer et al., 2013c), it should be clear that mobile learning for nurses and other health professionals cannot be considered a (cheap) substitute but should be viewed as a complementary approach to formal on-site education systems.

\section{Strengths, Weaknesses and Suggestions for Future Work}

The findings of this research were strengthened by a process of independent coding by three researchers from social and nursing sciences, by using the technique of respondent validation and by contrasting the data with existing social science theories (Giacomini and Cook, 2000; Mays and Pope, 2000). Due to the limited scope of this research, we are not able to offer definite accounts of the phenomenon at hand.

Given the methodological limitations of the present work, future studies should (1a) quantitatively measure the impact of mobile learning on professional isolation, problem-solving abilities and patient treatment, including its impact on health; and (1b) further explore and refine learning/teaching methods (such as scaffolding and PBL) based on mobile social media. Future work may also (2) observe different target groups (e.g., younger nurses in basic education, doctors, and community health workers); and (3) explore the phenomenon in other cultural, geographical and socio-economic settings.

From a theoretical standpoint, we argue that more analytical attention should be paid to the transformed learning environments and the affordances that mobile phones offer as tools in connecting multiple on- and offline communities and knowledge resources in problem solving and learning processes. This is not limited to resource-constrained regions, but it may well apply to "Western" systems such as the UK's National Health Service, in which learning in communities has recently been characterized by increased individualization, as well as geographical, hierarchical, and administrative distance (Spilg et al., 2012).

\section{Conclusions}

This investigation has shown that nursing students in resource poor settings use mobile technology as educational tools. These learning practices involve socio-cognitive processes, i.e., learning in the form of joint problem solving and reflection, as well as more intensive forms of socio-cultural participation in distributed, education and workrelated communities. In order for educational institutions to more fully and more systematically harness the potentialities of these media, a number of ethical and practical issues need to be addressed.

\section{Acknowledgments}

The authors thank Ms. Thandiwe Ndebele and all research participants, the project sponsors: the Rectors' Conference of the Swiss
Universities of Applied Sciences (KFH) and the Swiss Agency for Development and Cooperation SDC for their support of this work.

\section{References}

Abbott, P.A., Coenen, A., 2008. Globalization and advances in information and communication technologies: the impact on nursing and health. Nurs. Outlook 56, 238-246 (e232)

Berle, I., 2008. Clinical photography and patient rights: the need for orthopraxy. J. Med. Ethics 34, 89-92.

Bhangoo, P., Maconochie, I., Batrick, N., Henry, E., 2005. Clinicians taking pictures-a survey of current practice in emergency departments and proposed recommendations of best practice. Emerg. Med. J. 22, 761-765.

Brown, A.D., 2010. Social media: a new frontier in reflective practice. Med. Educ. 44, 744-745.

Cazden, C., Cope, B., Fairclough, N., Gee, J., Kalantzis, M., Kress, G., Luke, A., Luke, C., Michaels, S., Nakata, M., 1996. A pedagogy of multiliteracies: designing social futures. Harv. Educ. Rev. 66, 60-92.

Chib, A., 2010. The Aceh Besar midwives with mobile phones project: design and evaluation perspectives using the information and communication technologies for healthcare development model. J. Comput. Mediat. Commun. 15, 500-525.

Clay, C.A., 2011. Exploring the use of mobile technologies for the acquisition of clinical skills. Nurse Educ. Today 31, 582-586.

Coovadia, H., Jewkes, R., Barron, P., Sanders, D., McIntyre, D., 2009. The health and health system of South Africa: historical roots of current public health challenges. Lancet 374, 817-834.

Garrett, B.M., Jackson, C., 2006. A mobile clinical e-portfolio for nursing and medical students, using wireless personal digital assistants (PDAs). Nurse Educ. Today 26, 647-654.

Garrett, B., Klein, G., 2008. Value of wireless personal digital assistants for practice: perceptions of advanced practice nurses. J. Clin. Nurs. 17, 2146-2154.

Garrison, D.R., Anderson, T., Archer, W., 1999. Critical inquiry in a text-based environment: computer conferencing in higher education. Internet High. Educ. 2, 87-105.

George, L.E., Davidson, L.J., Serapiglia, C.P., Barla, S., Thotakura, A., 2010. Technology in nursing education: a study of PDA use by students. J. Prof. Nurs. 26, 371-376.

Giacomini, M.K., Cook, D.J., 2000. Users' guides to the medical literature. Qualitative research in health care. Are the results of the study valid? JAMA 284, 357-362.

Green, A., 2006. Nursing and midwifery: millennium development goals and the global human resource crisis. Int. Nurs. Rev. 53, 13-15.

Holmes, D., 2010. Rwanda: an injection of hope. Lancet 376, 945-946.

ITU Press Release, 2010. International Telecommunication Union (Barcelona).

Jordan, B., 1989. Cosmopolitical obstetrics: some insights from the training of traditional midwives. Soc. Sci. Med. 28, 925-937.

Kenny, R.F., Park, C., Van Neste-Kenny, J.M., Burton, P.A., Meiers, J., 2009. Using mobile learning to enhance the quality of nursing practice education. Mobile Learning Transforming the delivery of education and training pp. 75-98.

Kirschner, P.A., 2006. (Interdependent) Learning. Learning is Interaction. Inaugural AddressCip-gegevens Koninklijke Bibliotheek, Den Haag, Utrecht.

Laurillard, D., 2009. The pedagogical challenges to collaborative technologies. Int. J. Comput.-Support. Collab. Learn. 4, 5-20.

Lave, J., Wenger, E., 1991. Situated Learning. Legitimate Peripheral Participation. University of Cambridge Press, Cambridge.

Livingstone, S., 2004. What is media literacy? Intermedia 32, 18-20.

Mayne, L.A., Wu, Q., 2011. Creating and measuring social presence in online graduate nursing courses. Nurs. Educ. Perspect. 32, 110-114.

Mayring, P., 2000. Qualitative content analysis. Forum Qualitative Sozialforschung / Forum: Qualitative Social Research Citeseer.

Mayring, P., 2004. Qualitative content anaiysis. In: Flick, U., von Kardorff, E., Steinke, I. (Eds.), A Companion to Qualitative Research. SAGE Publications Ltd., London, Thousand Oaks, New Delhi, pp. 266-269.

Mays, N., Pope, C., 2000. Qualitative research in health care: assessing quality in qualitative research. Br. Med. J. 320, 50-52.

Morley, D.A., 2013. Supporting student nurses in practice with additional online communication tools. Nurse Educ. Pract. 14 (10), 69-75.

Norman, G.R., Schmidt, H.G., 1992. The psychological basis of problem-based learning: a review of the evidence. Acad. Med. 67, 557.

Pachler, N., Bachmair, B., Cook, J., 2010. Mobile Learning: Structures, Agency, Practices. Springer, New York, Dordrecht, Heidelberg, London.

Patton, M.Q., 1990. Qualitative Research and Evaluation Methods. Sage Publications,Inc., Thousand Oaks.

Pimmer, C., Pachler, N., 2013. Mobile learning in the workplace. Unlocking the value of mobile technology for work-based education. In: Ally, M., Tsinakos, A. (Eds.), Mobile Learning Development for Flexible Learning. Commonwealth of Learning Press.

Pimmer, C., Pachler, N., Attwell, G., 2010. Towards work-based mobile learning: what we can learn from the fields of work-based learning and mobile learning. Int. J. Mob. Blended Learn. 2, 1-18.

Pimmer, C., Linxen, S., Gröhbiel, U., 2012. Facebook as a learning tool? A case study on the appropriation of social network sites along with mobile phones in developing countries. Br. J. Educ. Technol. 43, 726-738.

Pimmer, C., Linxen, S., Gröhbiel, U., Jha, A., Burg, G., 2013a. Mobile learning in resourceconstrained environments. A case study of medical education. Med. Teach. 35, e1157-e1165.

Pimmer, C., Pachler, N., Genewein, U., 2013b. Contextual dynamics in clinical workplaces. Learning from doctor-to-doctor consultations. Med. Educ. 47, 463-475. 
Pimmer, C., Pachler, N., Genewein, U., 2013c. Reframing clinical workplace learning using the theory of distributed cognition. Acad. Med. 88, 1239-1245.

Pope, C., Ziebland, S., Mays, N., 2000. Qualitative research in health care: analysing qualitative data. Br. Med. J. 320, 114-116.

Raisler, J., Cohn, J., 2005. Mothers, midwives, and HIV/AIDS in Sub-Saharan Africa. J. Midwifery Womens Health 50, 275-282.

Seedat, M., 2006. Data to action: mobilising compassion and merging voices in safety promotion. African Safety Promotion. J. Inj. Violence Prev. 4, 7-21.

Slotnick, H.B., 1999. How doctors learn: physicians' self-directed learning episodes. Acad. Med. 74, 1106-1117.

Spilg, E., Siebert, S., Martin, G., 2012. A social learning perspective on the development of doctors in the UK National Health Service. Soc. Sci. Med. 75, 1617-1624.
The World Bank, 2012. Information and communications for development. Maximizing Mobile (Washington, DC).

WHO, 2010. Increasing access to health workers in remote and rural areas through improved retention. Global Policy Recommendations.

Wu, P.-H., Hwang, G.-J., Tsai, C.-C., Chen, Y.-C., Huang, Y.-M., 2011. A pilot study on conducting mobile learning activities for clinical nursing courses based on the repertory grid approach. Nurse Educ. Today 31, e8-e15.

Young P. Moore, E Griffiths, G, Raine, R, Stewart, R., Cownie, M., Frutos-Perez M, 2010. Help is just a text away: the use of short message service texting to provide an additional means of support for health care students during practice placements. Nurse Educ. Today 30, 118-123. 